\title{
Meminimasi Risiko pada Rantai Pasok Menggunakan Kerangka Kerja Suplly Chain Risk Management di PT. Adhi Chandra Dwiutama
}

\author{
Arief Irfan Syah Tjaja, Dio Rizcki Sekartyasto, Arif Imran \\ Jurusan Teknik Industri, Fakultas Teknologi Industri, ITENAS, Bandung \\ Email: ariefirfan75@gmail.com
}

\begin{abstract}
ABSTRAK
Rantai Pasok merupakan jaringan dari perusahaan- perusahaan yang bekerja secara bersama untuk menciptakan dan mengantarkan suatu produk ke konsumen akhir. Perusahaan - perusahaan tersebut bergerak di bidang supplier, manufaktur, distributor, ritel/toko dan perusahaan jasa logistik. Didalam rantai pasok terdiri dari berbagai aliran informasi yang harus dikelola oleh perusahaan. Oleh karena itu, untuk menciptakan rantai pasok yang terintegritas dan unggul perusahaan perlu mengelola rantai pasok dengan menggunakan supply chain management. Dalam proses rantai pasok, manajemen risiko rantai pasok dibutuhkan untuk mengendalikan risiko-risiko yang mungkin muncul agar tidak menggangu berjalannya rantai pasok. Proses manajemen risiko rantai pasok dimulai dengan identifikasi proses bisnis dalam rantai pasok, lalu mengidentifikasi risiko dalam proses bisnis. Kemudian dilakukan penilaian nilai konsekuensi dan probabilitas melalui kuesioner. Identifikasi risiko menghasilkan 64 risiko, 33 risiko dengan tingkat rendah, 21 dengan tingkat menengah, dan 10 tingkat tinggi. Setelah mendapatkan risiko berdasarkan tingkatannya, dilakukan perancangan mitigasi terhadap risiko yang paling tinggi.
\end{abstract}

Kata kunci : Rantai Pasok, Manajemen Risiko Rantai Pasok, Mitigasi

\begin{abstract}
Supply Chain is a network of companies that work together to create and deliver a product into the hands of the end user. These companies usually include suppliers, manufactur, distributors, retail / stores and logistic service companies. In the supply chain consists of various streams of information that must be managed by the company. Therefore, to create an integrated and superior supply chain, companies need to manage supply chains using supply chain management. In the supply chain, supply chain risk management is needed to control the risks that may happen in order not to disrupt supply chain. Supply chain risk management process begins with the identification of business processes in the supply chain, then identify risks in the business process. After that, a risk assessment is performed to assess the risk probability and consequences through the questionnaires. Risk identification brings out 64 risks, 33 lowrisk, 21 to medium-risk, and 10-high risk. After obtaining the risk based on its level,then do some design risk mitigation to the high-risk.
\end{abstract}

Keywords: Supply chain, supply chain risk management, mitigation 


\subsection{Pengantar}

\section{PENDAHULUAN}

Rantai Pasok merupakan jaringan dari perusahaan- perusahaan yang bekerja secara bersama untuk menciptakan dan mengantarkan suatu produk ke konsumen akhir (Pujawan dan Mahendrawati, 2017). Perusahaan- perusahaan tersebut termasuk supplier, pabrik, distributor, ritel/toko dan perusahaan jasa logistik. Di dalam rantai pasok terdapat tiga aliran yang dikelola. Pertama adalah aliran barang yang mengalir dari hulu ke hilir. Kedua adalah aliran uang dan sejenisnya yang mengalir dari hilir ke hulu. Ketiga adalah aliran informasi yang bias terjadi dari hulu ke hilir ataupun sebaliknya. Oleh karena itu, untuk menciptakan rantai pasok yang terintegrasi dan unggul perusahaan perlu mengelola rantai pasok dengan menggunakan supply chain management.

Supply Chain Management adalah sebuah metode, alat atau pendekatan pengelolaannya, berbeda dengan rantai pasok sebagai bentuk fisiknya [1]. Supply Chain Management menghendaki kolaborasi yang baik antara pihak internal dan eksternal. Kordinasi sangat diperlukan, karena baik pihak internal maupun eksternal pada intinya ingin memuaskan konsumen akhir. Dalam aktivitas manajemen rantai pasok, tidak dapat dihindarkan dari adanya ketidakpastian, ketidakpastian yang berampak negatif inilah yang dinamakan risiko.

PT. Adhi Chandra Dwiutama bergerak dalam industri percetakan. Produk yang dibuat oleh perusahaan ini salah satunya adalah label pakaian (hang tag). Perusahaan dapat memproduksi hangtag sebanyak 130.000 unit perbulannya. Jumlah kertas yang digunakan bisa menghabiskan 1806 unit berukuran plano. Perusahaan berusaha memberikan produk yang berkualitas pada konsumen, tetapi unsur ketidakpastian merupakan salah satu tantangan bagi perusahaan dalam mengelola rantai pasok resiko yang yang dapat memberi pengaruh terhadap pencapaian tujuan perusahaan.

Perusahaan perlu melakukan manajemen risiko yang terjadi selama aktivitas rantai pasok berlangsung agar tujuan yang ditetapkan perusahaan dapat dicapai. Menurut (COSO Entreprise Risk Management - Integrated Framework 2004, dikutip oleh [2], manajemen risiko merupakan proses, dipengaruhi oleh jajaran direksi entitas, manajemen dan personil lainnya, diterapkan dalam pengaturan strategi di setiap level perusahaan yang dirancang untuk mengidentifikasi kejadian potensial yang dapat mempengaruhi entitas, mengelola risiko berada dalam risk appetite-nya dan memberikan jaminan pencapaian tujuan entitas.

\subsection{Identifikasi Masalah}

Aktivitas rantai pasok yang dilakukan PT. Adhi Chandra Dwiutama melibatkan bebagai pihak, mulai dari meramalkan permintaan sebagai acuan untuk menentukan target produksi dan pembelian bahan baku, memeriksa kuantitas dan kualitas bahan baku dari supplier, melakukan proses produksi dan mengirim produk jadi yang telah selesai ke konsumen. Oleh karena itu, untuk menciptakan rantai pasok yang terintegrasi dan unggul perusahaan perlu mengelola rantai pasok dengan menggunakan supply chain risk management. Agar dapat mengetahui akar risiko- risiko apa saja yang mungkin terjadi dalam rantai pasok. Dengan melakukan hal tersebut perusahaan dapat mengetahui penyebab risiko- risiko yang terjadi dan mencari penyelesaian masalahnya. Perusahaan perlu melakukan manajemen risiko yang terjadi selama aktivitas rantai pasok berlangsung agar tujuan yang ditetapkan perusahaan dapat dicapai. 


\subsection{Manajemen Risiko}

\section{STUDI LITERATUR}

Manajemen risiko merupakan suatu kebijakan dan prosedur yang lengkap, yang dimiliki organisasi, untuk mengelola, memonitor, dan mengendalikan organisasi terhadap risiko [3]. Manajemen risiko itu sendiri memiliki beberapa tujuan. Namun inti dari manajemen risiko adalah untuk mengidentifikasi semua risiko yang potensial, kemudian menyusun perencanaan dan melakukan tindakan pencegahannya sebelum risiko-risiko tersebut terjadi.

\subsection{Konsep Risiko}

Kata 'Risiko' berasal dari salah satu antara dua Bahasa [4]. Pertama adalah kata 'risq' dari Bahasa Arab yang artinya adalah semua yang diberikan oleh Tuhan yang dapat menghasilkan keuntungan. Kedua adalah kata 'riscum' dari Bahasa Latin yang artinya tantangan dari karang penghalang besar bagi seorang nelayan. Manajemen risiko di definisikan sebagai usaha untuk mengenali dan mengelola masalah yang muncul secara tidak terduga di saat implementasi proyek [5].

\subsection{Risk Maps}

Tabel risk maps yang disusun berdasarkan penentuan level risiko menurut (Joint Australian/ New Zealand Standar 2004, dikutip oleh [2] dapat dilihat pada Tabel 1.

Tabel 1. Risk Maps

\begin{tabular}{cccccc}
\hline & \multicolumn{4}{c}{ Konsekuensi } \\
\cline { 2 - 5 } Probabilitas & Sangat & Ringan & Sedang & Besar & Ekstreme \\
& Ringan & 1 & 2 & 3 & 4 \\
& Medium & High & High & $\begin{array}{c}\text { Very } \\
\text { High }\end{array}$ & $\begin{array}{c}\text { Very } \\
\text { High }\end{array}$ \\
\hline \multirow{2}{*}{ Sangat Besar (5) } & Medium & Medium & High & High & Very \\
\hline Besar (4) & Low & Medium & High & High & High \\
\hline Sedang (3) & Low & Low & Medium & Medium & High \\
\hline Kecil (2) & Low & Low & Medium & Medium & High
\end{tabular}

\subsection{Manajemen Risiko Rantai Pasok}

Manajemen Risiko Rantai Pasok Adalah suatu proses yang sistematis untuk identifikasi, analisa, dan berurusan dengan risiko pada rantai pasok [6].

Tummala \& Schoenherr [7] membagi proses SCRM menjadi tiga fase utama yang tertera pada Gambar 1 sebagai berikut: 


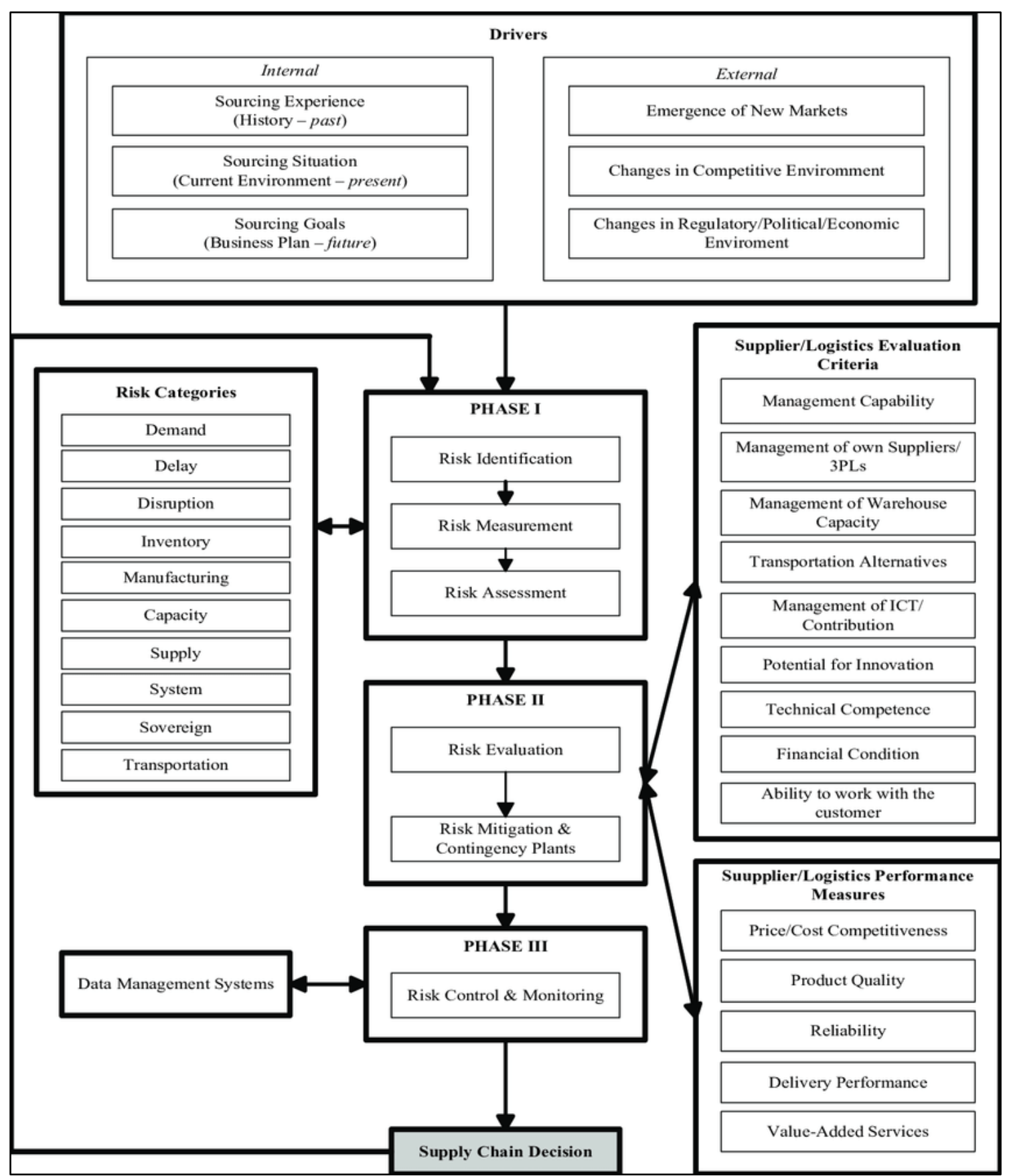

Gambar 1. Proses Supply Chain Risk Management

Dalam penggunaan metode manajemen risiko rantai pasok, terdapat dua fase, yaitu:

\section{Fase I Proses SCRM}

- Identifikasi Risiko

Langkah pertama dalam fase pertama proses SCRM adalah identifikasi risiko. Cara yang dapat digunakan untuk mengidentifikasi risiko adalah pertama dengan mengidentifikasi proses bisnis rantai suplai yang dilakukan oleh perusahaan berdasarkan elemen SCOR (Supply Chain Operations Reference). Berdasarkan SCOR, rantai suplai merupakan integrasi dari 5 elemen utama yaitu: Plan, Source, Make, Deliver, dan Return.

- Pengukuran Risiko 
Pengukuran risiko merupakan tahap kedua dalam fase pertama. Yang dilakukan pada tahap ini adalah mengukur nilai konsekuensi untuk setiap risiko yang mungkin muncul.

- $\quad$ Asesmen Risiko

Tahap terakhir pada fase pertama adalah asesmen risiko yaitu penghitungan nilai likelyhood risiko atau kemungkinan muncul risiko tersebut.

\section{Fase II Proses SCRM}

- Evaluasi Risiko

Evaluasi risiko adalah tahap pertama pada fase kedua dalam proses SCRM. Pada tahap ini dilakukan pemberian peringkat pada risiko. Pemberian peringkat didasarkan pada nilai paparan faktor risiko yaitu hasil perkalian antara indeks konsekuensi dengan indeks probabilitas.

- $\quad$ Mitigasi Risiko

Langkah mitigasi risiko meliputi mengidentifikasi opsi untuk penanganan risiko, menaksir opsi tersebut, menyiapkan rencana perlakua risiko, dan mengimplementasikan rencana perlakuan risiko. Pilihan penanganan risiko secara umum meliputi: Menghindari risiko (Risk Avoidance), Mengurangi risiko (Risk Reduction), Transfer Risiko (Risk Transfer), Membagi Risiko (Risk Sharing), dan Menerima Risiko (Risk Acceptance).

\subsection{Diagram Ishikawa}

Diagram Ishikawa atau cause and effect diagram adalah cara untuk mengilustrasikan hubungan antara penyebab dan dampak [8]. Dampak adalah karakteristrik dari kualitas dan penyebab adalah faktornya.

\section{METODOLOGI PENELITIAN}

Metodologi penelitian dapat dilihat di Gambar 2.

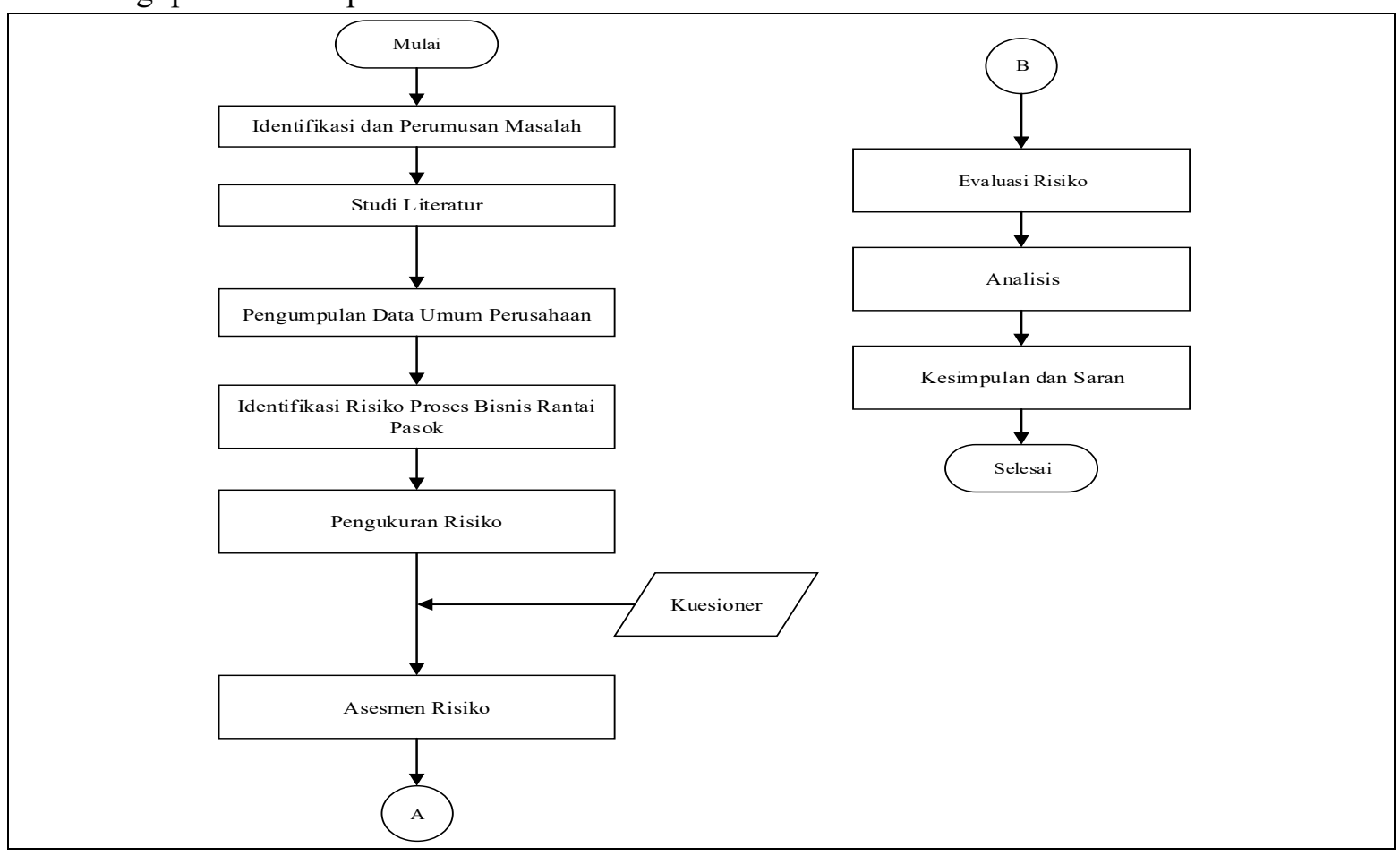

Gambar 2. Metodologi Penelitian 


\section{PENGOLAHAN DATA}

Proses identifikasi risiko menggunakan diagram cause and effect dilakukan setelah penjabaran proses bisnis menggunakan SCOR, yaitu Plan, Source, Make, Deliver, dan Return. Identifikasi risiko dapat dilihat pada Tabel 2.

Tabel 2. Penjabaran SCOR

\begin{tabular}{|c|c|c|c|c|}
\hline $\begin{array}{l}\text { Proses } \\
\text { Utama }\end{array}$ & Kode & Proses Bisnis & No. Risiko & Risiko \\
\hline \multirow{12}{*}{ Plan } & \multirow{4}{*}{ P.1 } & \multirow{4}{*}{$\begin{array}{l}\text { Menghitung harga pokok } \\
\text { produksi }\end{array}$} & R.1 & $\begin{array}{l}\text { Fluktuasi mata uang menyebabkan harga } \\
\text { meningkat }\end{array}$ \\
\hline & & & R.2 2 & $\begin{array}{l}\text { Biaya yang terjadi melebihi HPP yang } \\
\text { dirancang }\end{array}$ \\
\hline & & & R.3 & $\begin{array}{l}\text { Harga yang ditawarkan konsumen } \\
\text { dibawah Harga jual }\end{array}$ \\
\hline & & & R.4 & $\begin{array}{l}\text { Kesalahan dalam membuat perubahan } \\
\text { harga }\end{array}$ \\
\hline & \multirow{3}{*}{ P. 2} & \multirow{3}{*}{ Membuat gambar desain } & R.6 & $\begin{array}{l}\text { Keterlambatan dalam membuat gambar } \\
\text { karena data kurang detail }\end{array}$ \\
\hline & & & R.7 & $\begin{array}{l}\text { Kesalahan dalam membuat gambar } \\
\text { desain }\end{array}$ \\
\hline & & & R. 8 & $\begin{array}{l}\text { Membutuhkan waktu yang lama dalam } \\
\text { merubah gambar desain }\end{array}$ \\
\hline & \multirow{3}{*}{ P.3 } & \multirow{3}{*}{$\begin{array}{l}\text { Mengirimkan desain } \\
\text { gambar kepada konsumen }\end{array}$} & R.9 & $\begin{array}{l}\text { Desain yang dikirim tidak disetujui } \\
\text { konsumen }\end{array}$ \\
\hline & & & R. 10 & $\begin{array}{l}\text { Desain yang dikirim tidak diterima } \\
\text { tangan oleh konsumen }\end{array}$ \\
\hline & & & R.11 & $\begin{array}{l}\text { Desain yang ditawarkan tidak disetujui } \\
\text { konsumen }\end{array}$ \\
\hline & P.4 & $\begin{array}{l}\text { Melakukan pengecekan } \\
\text { stok bahan baku digudang }\end{array}$ & R.12 & $\begin{array}{l}\text { Barang yang tersedia digudang tidak } \\
\text { sesuai dengan data yang ada }\end{array}$ \\
\hline & P.5 & $\begin{array}{l}\text { Membuat jadwal kerja } \\
\text { produski }\end{array}$ & R.13 & $\begin{array}{l}\text { Proses produksi membutuhkan waktu } \\
\text { yang lebih lama dari jadwal kerja awal }\end{array}$ \\
\hline \multirow{6}{*}{ Source } & \multirow{3}{*}{ S.1 } & \multirow{3}{*}{$\begin{array}{l}\text { Pemesanan bahan baku dan } \\
\text { komponen pelengkap }\end{array}$} & R.14 & $\begin{array}{l}\text { Keterlambatan dalam memesan bahan } \\
\text { baku }\end{array}$ \\
\hline & & & R.15 & $\begin{array}{l}\text { Kesalahan dalam membuat purchase } \\
\text { requisition }\end{array}$ \\
\hline & & & R.16 & $\begin{array}{l}\text { Membutuhkan waktu yang lama dalam } \\
\text { membuat purchase requisition }\end{array}$ \\
\hline & \multirow{3}{*}{ S.1.1 } & \multirow{3}{*}{$\begin{array}{l}\text { Melakukan survei vendor } \\
\text { supplier }\end{array}$} & R.17 & Proses survei yang terlalu lama \\
\hline & & & R.18 & $\begin{array}{l}\text { Vendor yang ada tidak memenuhi } \\
\text { spesifikasi kualitas bahan baku }\end{array}$ \\
\hline & & & R.19 & $\begin{array}{l}\text { Bahan baku yang dicari tidak tersedia } \\
\text { atau kuantitasnya sedikit }\end{array}$ \\
\hline
\end{tabular}


Tabel 2. Penjabaran SCOR (Lanjutan)

\begin{tabular}{|c|c|c|c|c|}
\hline $\begin{array}{l}\text { Proses } \\
\text { Utama }\end{array}$ & Kode & Proses Bisnis & No. Risiko & Risiko \\
\hline \multirow{15}{*}{ Source } & \multirow{4}{*}{ S.1.2 } & \multirow{4}{*}{$\begin{array}{l}\text { Melakukan negosiasi } \\
\text { harga dengan supplier }\end{array}$} & R.20 & $\begin{array}{l}\text { Harga yang ditawarkan vendor lebih mahal } \\
\text { dari perkiraan }\end{array}$ \\
\hline & & & R.21 & $\begin{array}{l}\text { Negosiasi tidak menemukan kesepakatan } \\
\text { dengan vendor }\end{array}$ \\
\hline & & & R.22 & Negosiasi membutuhkan waktu yang lama \\
\hline & & & R.23 & Harga yang ditawarkan masih terlalu mahal \\
\hline & \multirow{4}{*}{ S.2 } & \multirow{4}{*}{ Menerima bahan baku } & R.24 & $\begin{array}{l}\text { Dana yang disediakan untuk membayar } \\
\text { kurang }\end{array}$ \\
\hline & & & R.25 & Bahan baku yang diterima terlambat datang \\
\hline & & & R.26 & $\begin{array}{l}\text { Jenis bahan baku yang datang tidak sesuai } \\
\text { dengan yang dipesan }\end{array}$ \\
\hline & & & R. 27 & $\begin{array}{l}\text { Jumlah bahan baku yang datang tidak sesuai } \\
\text { dengan yang dipesan }\end{array}$ \\
\hline & \multirow{4}{*}{ S.2.1 } & \multirow{4}{*}{$\begin{array}{l}\text { Menyimpan bahan baku } \\
\text { digudang }\end{array}$} & R.28 & $\begin{array}{l}\text { Gudang inventori tidak dapat menampung } \\
\text { bahan baku }\end{array}$ \\
\hline & & & R.29 & $\begin{array}{l}\text { Kerusakan bahan baku saat hendak } \\
\text { dimasukan kedalam gudang }\end{array}$ \\
\hline & & & R.30 & $\begin{array}{l}\text { Bahan baku disimpan terlalu lama karena } \\
\text { menunggu bahan baku sisanya }\end{array}$ \\
\hline & & & R.31 & $\begin{array}{l}\text { Pendataan bahan baku digudang dilakukan } \\
\text { tidak teliti }\end{array}$ \\
\hline & \multirow{3}{*}{ S.2.2 } & \multirow{3}{*}{$\begin{array}{l}\text { Membuat dokumen tanda } \\
\text { terima bahan baku }\end{array}$} & R.32 & $\begin{array}{l}\text { Kelalaian dalam membuat dokumen tanda } \\
\text { terima bahan baku }\end{array}$ \\
\hline & & & R.33 & $\begin{array}{l}\text { Bahan baku memiliki kualitas bahan yang } \\
\text { tidak sesuai spesifikasi/ cacat }\end{array}$ \\
\hline & & & R.34 & $\begin{array}{l}\text { Pembuatan dokumen membutuhkan waktu } \\
\text { yang lama }\end{array}$ \\
\hline \multirow{8}{*}{ Make } & \multirow{5}{*}{ M.1 } & \multirow{5}{*}{$\begin{array}{l}\text { Melakukan proses } \\
\text { pemesinan bahan baku, } \\
\text { setup mesin }\end{array}$} & R.35 & Mesin mengalami kerusakan \\
\hline & & & R.36 & Kecelakaan kerja operator \\
\hline & & & R.37 & Kapasitas mesin tidak mencukupi \\
\hline & & & R.38 & Stasiun kerja banyak yang menganggur \\
\hline & & & R.39 & Stasiun kerja penuh dengan proses lain \\
\hline & \multirow{3}{*}{ M.2 } & \multirow{3}{*}{$\begin{array}{l}\text { Melakukan uji kelayakan } \\
\text { produk }\end{array}$} & R.40 & Produk tidak lolos uji kelayakan \\
\hline & & & R.41 & $\begin{array}{l}\text { Kesalahan/ kelalaian dalam melakukan uji } \\
\text { kelayakan }\end{array}$ \\
\hline & & & R.42 & Kesalahan dalam mencatat hasil pemeriksaan \\
\hline
\end{tabular}


Tabel 2. Penjabaran SCOR (Lanjutan)

\begin{tabular}{|c|c|c|c|c|}
\hline $\begin{array}{l}\text { Proses } \\
\text { Utama }\end{array}$ & Kode & Proses Bisnis & No. Risiko & Risiko \\
\hline \multirow{4}{*}{ Make } & \multirow{4}{*}{ M.3 } & \multirow{4}{*}{$\begin{array}{l}\text { Menyimpan produk } \\
\text { barang jadi }\end{array}$} & R.43 & Kemasan produk cacat/rusak \\
\hline & & & R.44 & Kemasan produk kurang \\
\hline & & & R.45 & $\begin{array}{l}\text { Kerusakan produk dalam proses } \\
\text { penyimpanan barang jadi }\end{array}$ \\
\hline & & & R.46 & $\begin{array}{l}\text { Kesalahan dalam membuat dokumen barang } \\
\text { jadi }\end{array}$ \\
\hline \multirow{9}{*}{ Deliver } & \multirow{3}{*}{ D. 1} & \multirow{3}{*}{$\begin{array}{l}\text { Memilih jenis angkutan } \\
\text { yang digunakan }\end{array}$} & R.47 & Transportasi tidak tersedia \\
\hline & & & R.48 & $\begin{array}{l}\text { Bahan bakar kendaraan naik sehingga ongkos } \\
\text { naik }\end{array}$ \\
\hline & & & R.49 & $\begin{array}{l}\text { Kapasitas transportasi yang tersedia tidak } \\
\text { mencukupi jumlah pengiriman }\end{array}$ \\
\hline & \multirow{4}{*}{ D. 2} & \multirow{4}{*}{ Mengirim barang jadi } & R.50 & $\begin{array}{l}\text { Terjadi kesalahan barang dalam mengirim } \\
\text { barang }\end{array}$ \\
\hline & & & R.51 & $\begin{array}{l}\text { Terjadi keterlambatan pengiriman barang ke } \\
\text { konsumen }\end{array}$ \\
\hline & & & R.52 & $\begin{array}{l}\text { Terjadi kerusakan barang dalam pengiriman } \\
\text { barang }\end{array}$ \\
\hline & & & R.53 & $\begin{array}{l}\text { Terjadi kesalahan alamat dalam tujuan } \\
\text { pengiriman barang }\end{array}$ \\
\hline & \multirow{2}{*}{ D.2.1 } & \multirow{2}{*}{$\begin{array}{l}\text { Membuat surat } \\
\text { pengiriman barang jadi }\end{array}$} & R.54 & $\begin{array}{l}\text { Kesalahan dalam membuat surat pengiriman } \\
\text { barang jadi }\end{array}$ \\
\hline & & & R.55 & $\begin{array}{l}\text { Proses pembuatan surat lama, sehingga surat } \\
\text { izin telat keluar }\end{array}$ \\
\hline \multirow{5}{*}{ Return } & \multirow{3}{*}{ Re.1 } & \multirow{3}{*}{$\begin{array}{l}\text { Melakukan } \\
\text { pengembalian bahan } \\
\text { baku ke supplier }\end{array}$} & R.56 & Pembuatan surat pengembalian terlalu lama \\
\hline & & & R.57 & $\begin{array}{l}\text { Keterlambatan dalam mengirim bahan baku } \\
\text { ke vendor }\end{array}$ \\
\hline & & & R.58 & $\begin{array}{l}\text { Bahan baku tidak diterima kembali oleh } \\
\text { vendor }\end{array}$ \\
\hline & \multirow[t]{2}{*}{ Re.1.2 } & \multirow{2}{*}{$\begin{array}{l}\text { Menerima komplain dari } \\
\text { konsumen }\end{array}$} & R.59 & $\begin{array}{l}\text { Konsumen kecewa dan tidak memakai jasa } \\
\text { perusahaan lagi }\end{array}$ \\
\hline & & & R.60 & Komplain tidak terdata dicatatan perusahaan \\
\hline
\end{tabular}

Setelah risiko teridentifikasi, langkah selanjutnya adalah melakukan penilaian terhadap risiko berdasarkan perkalian antara nilai probabilitas dan konsekuensi yang didapatkan melalui kuesioner berdasarkan nilai skala dan kriteria yang sudah ditetapkan. Hasil yang didapatkan digunakan untuk memetakan risiko berdasarkan tingkatannya didalam risk maps yang dapat dilihat pada Tabel 3. 
Tabel 3. Risk Maps

\begin{tabular}{|c|c|c|c|c|c|}
\hline & \multicolumn{5}{|c|}{ Konsekuensi } \\
\hline Probabilitas & $\begin{array}{c}\text { Sangat Ringan } \\
\text { (1) }\end{array}$ & Ringan (2) & Sedang (3) & Berat (4) & Ekstreme (5) \\
\hline Sangat Besar (5) & & & & & \\
\hline Besar (4) & R.23 & R.28 & R.35 & & \\
\hline Sedang (3) & R.34 & R. 2 R.4 R.37 & $\begin{array}{l}\text { R. } 3 \text { R.12 R.13 } \\
\text { R.26 R. } 27\end{array}$ & R.20 & \\
\hline Kecil (2) & $\begin{array}{l}\text { R.42 R.51 R.53 } \\
\text { R.54 R.57 }\end{array}$ & $\begin{array}{l}\text { R.5 R.8 R.19 R.31 } \\
\text { R.43 R.45 R.59 }\end{array}$ & R.7 R.17 R.21 & R.25 & \\
\hline Sangat Kecil (1) & $\begin{array}{l}\text { R. } 29 \text { R.30 R.42 } \\
\text { R.33 R.41 R.48 } \\
\text { R.56 R. } 60\end{array}$ & $\begin{array}{l}\text { R.22 R.9 R.10 R.11 } \\
\text { R.26 R.27 R.35 R.38 } \\
\text { R.40 R.44 R.46 R.49 }\end{array}$ & $\begin{array}{l}\text { R.1 R.6 R.14 } \\
\text { R.16 R.47 R.52 } \\
\text { R.55 }\end{array}$ & $\begin{array}{l}\text { R. } 15 \text { R. } 18 \\
\quad \text { R. } 49\end{array}$ & R.24 R.36 R.59 \\
\hline
\end{tabular}

\section{ANALISIS}

Berdasarkan permintaan perusahaan, terdapat beberapa risiko yang diminta untuk dilakukan tindakan pencegahan melalui usulan mitigasi yang dapat dilihat pada Tabel 4 sampai Tabel 11.

\section{R.3 Harga yang ditawarkan konsumen dibawah Harga jual}

Tabel 4. Usulan Pencegahan Risiko R.3

\begin{tabular}{lll}
\hline $\begin{array}{c}\text { No. } \\
\text { Risiko }\end{array}$ & \multicolumn{1}{c}{ Risiko } & \multicolumn{1}{c}{ Tindakan } \\
\hline R.3 & Harga yang ditawarkan & Risk Reduction Risiko : \\
& $\begin{array}{l}\text { konsumen dibawah Harga } \\
\text { jual }\end{array}$ & $\begin{array}{l}\text { Melakukan negosiasi harga dengan pelanggan hingga mencapai } \\
\text { titik ekuilibrum (keseimbangan) }\end{array}$ \\
\hline
\end{tabular}




\section{R.12 Barang yang tersedia digudang tidak sesuai dengan data yang ada}

Tabel 5. Usulan Pencegahan Risiko R.12

\begin{tabular}{llll}
\hline $\begin{array}{c}\text { No. } \\
\text { Risiko }\end{array}$ & \multicolumn{1}{c}{ Risiko } & & \multicolumn{1}{c}{ Tindakan } \\
\hline R.12 & Barang yang tersedia & Risk & Reduction Risiko : \\
& digudang tidak sesuai & $\bullet$ & Perbaikan SOP dalam prosedur pengecekan bahan baku \\
& dengan data yang ada & & digudang. \\
& & & Perusahaan harus melakukan sosialisasi SOP kepada bagian \\
& & & supervisor pengadaan dan bawahannya. \\
& & & Pelanggaran SOP bisa juga dilakukan dengan punishment \\
& & & \\
& & & \\
& & &
\end{tabular}

R.13 \& R.35 Proses produksi membutuhkan waktu yang lebih lama dari jadwal kerja Awal \& Mesin mengalami kerusakan

Tabel 6. Usulan Pencegahan Risiko R.13 \& R.35

\begin{tabular}{|c|c|c|}
\hline $\begin{array}{c}\text { No. } \\
\text { Risiko }\end{array}$ & Risiko & Tindakan \\
\hline $\begin{array}{l}\text { R.13 \& } \\
\text { R.35 }\end{array}$ & $\begin{array}{l}\text { Proses produksi } \\
\text { membutuhkan } \\
\text { waktu yang lebih } \\
\text { lama dari jadwal } \\
\text { kerja awal \& } \\
\text { Mesin } \\
\text { mengalami } \\
\text { kerusakan }\end{array}$ & $\begin{array}{l}\text { Risk Reduction Risiko : } \\
\text { - Penggunaan software scheduling seperti JustPlanIt, dimana dengan } \\
\text { menggunakan software tersebut diharapkan proses penjadwalan dapat } \\
\text { terperinci. } \\
\text { - Follow up dari bagian supervisor teknik secara berkala. } \\
\text { - Perusahaan harus melakukan penjadwalan perawatan mesin secara } \\
\text { berkala untuk membuat mesin tetap pada kondisi yang optimal. } \\
\text { - Perusahaan dapat memfasilitasi karyawannya untuk mempelajari cara } \\
\text { merawat mesin. }\end{array}$ \\
\hline
\end{tabular}

\section{R.20 Harga yang ditawarkan vendor lebih mahal dari perkiraan}

Tabel 7. Usulan Pencegahan Risiko R.20

\begin{tabular}{|c|c|c|}
\hline $\begin{array}{c}\text { No. } \\
\text { Risiko }\end{array}$ & Risiko & Tindakan \\
\hline R.20 & $\begin{array}{l}\text { Harga yang } \\
\text { ditawarkan } \\
\text { vendor lebih } \\
\text { mahal dari } \\
\text { perkiraan }\end{array}$ & $\begin{array}{l}\text { Risk Reduction Risiko : } \\
\text { - Perusahaan melakukan negosiasi berdasarkan harga yang mampu } \\
\text { dibayarkan oleh perusahaan. } \\
\text { - Perusahaan mencari vendor lain yang dapat menyediakan jenis dan } \\
\text { kualitas yang sama dengan harga yang lebih rendah. }\end{array}$ \\
\hline
\end{tabular}




\section{R.24 Dana yang disediakan untuk membayar kurang}

Tabel 8. Usulan Pencegahan Risiko R.24

\begin{tabular}{|c|c|c|}
\hline $\begin{array}{c}\text { No. } \\
\text { Risiko }\end{array}$ & Risiko & Tindakan \\
\hline R.24 & $\begin{array}{l}\text { Dana yang } \\
\text { disediakan } \\
\text { untuk } \\
\text { membayar } \\
\text { kurang }\end{array}$ & $\begin{array}{l}\text { Risk Reduction Risiko: } \\
\text { - Menyiapkan dana sejak penawaran diterima dengan pelanggan dan } \\
\text { melebihkan dana untuk kebutuhan bahan baku mendesak. } \\
\text { Risk Sharing Risiko : } \\
\text { - } \text { Masalah keuangan yang dialami oleh bagian pengadaan dapat dibicarakan } \\
\text { dengan divisi keuangan }\end{array}$ \\
\hline
\end{tabular}

R.26 \& R.27 Jenis dan Jumlah bahan baku yang datang tidak sesuai dengan yang dipesan

Tabel 9. Usulan Pencegahan Risiko R.26 dan R.27

\begin{tabular}{|c|c|c|}
\hline $\begin{array}{c}\text { No. } \\
\text { Risiko }\end{array}$ & Risiko & Tindakan \\
\hline R.26 & Jenis dan jumlah & Risk Reduction Risiko: \\
\hline \& R.27 & $\begin{array}{l}\text { bahan baku yang } \\
\text { datang tidak } \\
\text { sesuai dengan } \\
\text { yang dipesan }\end{array}$ & $\begin{array}{l}\text { - Perusahaan melakukan follow up yang dilakukan antara bagian produksi } \\
\text { dengan bagian pengadaan dibarengkan dengan follow up yang lebih } \\
\text { intens kepada pihak vendor. } \\
\text { - Negosiasi dengan pihak vendor adalah melakukan penukaran bahan baku } \\
\text { dengan pihak vendor. }\end{array}$ \\
\hline
\end{tabular}

\section{R.36 Kecelakaan kerja operator}

Tabel 10. Usulan Pencegahan Risiko R.36

\begin{tabular}{lll}
\hline $\begin{array}{c}\text { No. } \\
\text { Risiko }\end{array}$ & \multicolumn{1}{c}{ Risiko } & \multicolumn{1}{c}{ Tindakan } \\
\hline R.36 & Kecelakaan kerja & $\begin{array}{r}\text { Risk Reduction Risiko : } \\
\text { operator }\end{array}$ \\
& $\begin{array}{l}\text { Perusahaan dapat memfasilitasi karyawannya untuk menambah } \\
\text { keahlian dalam penggunaan mesin. }\end{array}$ \\
\hline
\end{tabular}

\section{R.59 Konsumen kecewa dan tidak memakai jasa perusahaan lagi}

Tabel 11. Usulan Pencegahan Risiko R.59

\begin{tabular}{|c|c|c|}
\hline $\begin{array}{c}\text { No. } \\
\text { Risiko }\end{array}$ & Risiko & Tindakan \\
\hline R.59 & $\begin{array}{l}\text { Konsumen kecewa } \\
\text { dan tidak memakai } \\
\text { jasa perusahaan lagi }\end{array}$ & $\begin{array}{l}\text { Risk Reduction Risiko : } \\
\text { - Perusahaan memperbaiki kinerja pelayanan dari awal konsumen } \\
\text { memesan hingga produk sampai ke tangan konsumen. }\end{array}$ \\
\hline
\end{tabular}




\section{KESIMPULAN}

Berdasarkan penelitian yang dilakukan di PT. Adhi Chandra Dwiutama mengenai pencegahan risiko pada rantai pasok, diperoleh hasil identifikasi risiko sebanyak 60 risiko. Hasil dari pemetaan yang dilakukan dan perhitungan antara nilai probabilitas dan nilai konsekuensi, didapatkan 3 tingkatan risiko dengan 31 risiko tingkat rendah, 19 risiko dengan tingkat menengah, dan 10 risiko. Bentuk mitigasi yang digunakan untuk pencegahan risiko adalah menghindari risiko (Risk Avoidance), mengurangi risiko (Risk Reduction), transfer risiko (Risk Transfer), membagi risiko (Risk Sharing) dan menerima risiko (Risk Acceptance)

\section{DAFTAR PUSTAKA}

[1] Pujawan, I. N., \& Mahendrawathi. (2017). Supply Chain Management. Surabaya: Guna Widya.

[2] Pardjo Yap (2017). Manajemen Risiko Perusahaan. Jakarta: Growing Publishing.

[3] Warburg, S. (2004). Prespective in Supply Chain Risk Management. Los Angeles: UCLA.

[4] Merna, T., \& Thani, F. A. (2011). Corporate Risk Management (2nd ed.). West Sussex: John.

[5] Larson, E. W., \& Gray, C. F. (2011). Project Management: The Managerial Process (5thed.). New York: The McGraw-Hill Companies, Inc.

[6] Khan, O., \& Zsidisin, G. A. (2012). Handbook For Supply Chain Risk Management. Amerika Serikat: J. Ross Publishing.

[7] Tummala, R., \& Schoenherr, T. (2011). Assessing and Managing Risks Using the Supply Chain Risk Management Process (SCRMP)', Supply Chain Management: An International Journal, vol.16, no.6, .

[8] Ishikawa, D. K. (1990). Guide to Quality Control. Tokyo: Asian Productivity Organization. 